\title{
PELATIHAN MODEL PEMBELAJARAN QUICK ON THE DRAW DAN SAVI BAGI GURU MATEMATIKA SMP SEKABUPATEN BANJAR
}

\author{
lin Ariyanti ${ }^{*}$, Rahmatya Nurmeidina ${ }^{2}$ \\ ${ }^{1 *}$ Program Studi Pendidikan Matematika, Universitas Muhammadiyah Banjarmasin \\ ${ }^{2}$ Program Studi Pendidikan Matematika, Universitas Muhammadiyah Banjarmasin \\ Corresponding author : \\ E-mail : iin.ariyanti1105@gmail.com
}

Diterima 11 April 2019, Disetujui 17 April 2019

\begin{abstract}
ABSTRAK
Dalam merancang pelaksanaan pembelajaran matematika, dibutuhkan kemampuan guru dalam menentukan model-model pembelajaran yang sesuai dengan materi dan karakteristik peserta didik untuk mencapai tujuan pembelajaran yang diharapkan. Penerapan pembelajaran matematika di sekolah pada umumnya masih didominasi pembelajaran yang berpusat pada guru. Guru-guru masih jarang menerapkan model pembelajaran yang bervariasi pada proses pembelajaran matematika. Oleh karena itu, solusi yang ditawarkan berupa kegiatan pelatihan model-model pembelajaran bagi guru-guru matematika SMP Sekabupaten Banjar. Metode pelaksanaan kegiatan ini terdiri dari tahap persiapan dan pelaksanaan. Materi yang diberikan berupa 1) pengertian model pembelajaran beserta kaitannya dengan pendekatan, strategi, dan metode pembelajaran; 2) jenis-jenis model pembelajaran yaitu Quick on the draw dan SAVI. Pelaksanaan kegiatan ini berjalan dengan lancar dan mendorong guru-guru matematika SMP sekabupaten Banjar untuk memperluas pengetahuan mereka mengenai jenis-jenis model pembelajaran untuk diterapkan dalam pembelajaran matematika.
\end{abstract}

Kata kunci: Pengabdian Masyarakat, Pelatihan, Model-Model Pembelajaran

\begin{abstract}
In designing the implementation of mathematics learning, it takes the teacher's ability to determine learning models that are in accordance with the material and characteristics of students to achieve the expected learning goals. The application of mathematics learning in schools in general is still dominated by teachercentered learning. Teachers still rarely apply a varied learning model to the mathematics learning process. Therefore, the solutions offered was training activity about learning models for all junior high school mathematics teachers in Kabupaten Banjar. The method of implementing this activity consists of the preparation and implementation stages. The material provided is 1) understanding of the learning model and its relation to approaches, strategies, and learning methods; 2) types of learning models, such as Quick on the draw and SAVI. The implementation of this activity went smoothly and encouraged junior high school mathematics teachers in the Kabupaten Banjar to increase their knowledge of the types of learning models to be applied in mathematics learning.
\end{abstract}

Keywords: Community service, Training, Learning Models

\section{PENDAHULUAN}

Dalam melaksanakan pembelajaran matematika di kelas, guru perlu menyiapkan perangkat pembelajaran secara tertulis berupa rencana pelaksanaan pembelajaran (RPP). RPP merupakan perencanaan jangka pendek untuk memproyeksikan apa yang akan dilakukan dalam pembelajaran dengan mencakup beberapa komponen diantaranya kompetensi dasar, indikator, tujuan pembelajaran, materi, langkahlangkah kegiatan yang terdiri dari kegiatan pendahuluan, kegiatan inti, dan penutup, alokasi waktu, sumber belajar, dan evaluasi pembelajaran (Kusrini, Manoy, Susanah, \& Wijayanti, 2015).
Penyusunan RPP membutuhkan kemahiran guru dalam menentukan pendekatan, strategi, metode, dan model yang tepat dengan menyesuaikan karakteristik peserta didik dan materi yang diajarkan. Pemilihan model, pendekatan, strategi, metode maupun teknik yang digunakan oleh guru dalam merancang RPP akan berpengaruh terhadap ketercapaian tujuan pembelajaran. Selain itu, matematika tergolong sulit dan ditakuti oleh siswa maka dibutuhkan strategi khusus agar siswa mampu mengikuti pembelajaran dan tercapai tujuan pembelajaran yang diharapkan. Oleh karena itu, dibutuhkan penguasaan konsep guru matematika mengenai jenis-jenis model 
pembelajaran sebagai bahan acuan yang dapat digunakan dalam penyusunan RPP.

Berdasarkan diskusi dengan mitra, diketahui penerapan pembelajaran matematika di sekolah masih dominan menggunakan pembelajaran yang berpusat pada guru. Guruguru masih jarang menerapkan model pembelajaran yang bervariasi pada proses pembelajaran matematika.Oleh karena itu, ditawarkan solusi berupa kegiatan pelatihan model-model pembelajaran bagi guru-guru matematika SMP sekabupaten Banjar.

Dengan adanya kegiatan pengabdian ini diharapkan memberikan manfaat yaitu sebagai berikut.

1. Menambah wawasan dan keterampilan guruguru matematika sekabupaten Banjar terhadap jenis-jenis model pembelajaran

2. Memotivasi guru-guru matematika sekabupaten Banjar untuk menerapkan modelmodel pembelajaran yang bervariasi.

3. Memotivasi guru-guru untuk memperluas pengetahuan mereka terhadap jenis-jenis model pembelajaran yang sesuai diterapkan dalam pembelajaran matemaika

\section{METODE PELAKSANAAN}

Pelaksanaan pengabdian ini terdiri dari persiapan dan pelaksanaan. Adapun kegiatan persiapan diantaranya adalah melakukan diskusi antara tim pengabdian dengan mitra mengenai permasalahan yang dihadapi oleh guru di sekolah beserta solusi yang ditawarkan oleh tim pengabdian untuk mengatasi permasalahan tersebut. Dari hasil diskusi tersebut, mitra meminta untuk diadakannya kegiatan pelatihan model-model pembelajaran. Selanjutnya, tim pengabdian melakukan kajian pustaka terkait model-model pembelajaran yang dapat digunakan oleh guru matematika dalam pembelajaran di sekolah. Kegiatan pelaksanaan merupakan inti dari kegiatan pengabdian ini yaitu pelatihan model-model pembelajaran menggunakan metode ceramah dan tanya jawab. Adapun materi yang disampaikan antara lain pengertian pendekatan, strategi, metode, dan model pembelajaran dan dilanjutkan dengan jenis-jenis model pembelajaran.

\section{HASIL DAN PEMBAHASAN}

Kegiatan pengabdian ini dilaksanakan pada hari kamis 21 Maret 2019 yang bertempat di SMPN 1 Martapura, Kabuapten Banjar, Kalimantan Selatan. Peserta kegiatan pengabdian masyarakat ini terdiri dari guru-guru matematika sekabupaten Banjar sebanyak 44 orang guru yang hadir. Kegiatan diawali dengan sambutan oleh perwakilan mitra dan tim pengabdian. Selanjutnya, tim pengabdian mengisi materi pelatihan model-model pembelajaran. Materi diawali dengan pengertian model pembelajaran dan kaitannya dengan pendekatan, strategi, dan metode yang ringkasnya adalah sebagai berikut. Model pembelajaran adalah kerangka kerja konseptual tentang pembelajaran. Model pembelajaran lebih luas dari pendekatan, strategi, dan sebagainya karena dalam suatu model pembelajaran dapat memuat pendekatan pembelajaran, strategi pembelajaran, metode pembelajaran, serta teknik dan taktik pembelajaran (Kusrini, Manoy, Susanah, \& Wijayanti, 2015). Istilah pendekatan berasal dari bahasa inggris "approach" yang memiliki arti pendekatan atau dalam dunia pengajaran dapat diartikan sebagai cara umum yang ditempuh guru dalam proses membelajarkan siswa. Strategi pembelajaran merupakan suatu rencana tindakan yang termasuk penggunaan metode dan pemanfaatan berbagai sumber daya atau kekuatan dalam pembelajaran. Metode adalah cara yang digunakan untuk mengimplementasikan rencana yang sudah disusun dalam kegiatan nyata agar tujuan yang telah disusun tercapai secara optimal. Hal ini berarti metode digunakan untuk merealisasikan strategi yang telah ditetapkan. Sedangkan model pembelajaran merupakan bentuk pembelajaran yang tergambar dari awal sampai akhir yang disajikan secara khas oleh guru dan merupakan penerapan suatu pendekatan, strategi, metode, dan teknik pembelajaran (Majid, 2013).

Selanjutnya, tim pengabdian melanjutkan materi terkait jenis-jenis model pembelajaran. Adapun model-model pembelajaran yang diberikan diantaranya model pembelajaran Quick on The Draw dan SAVI (Somatic, Auditory, Visual, dan Intelektual).

\section{Model Pembelajaran Quick on The Draw}

Model pembelajaran Quick on the draw diperkenalkan pertama kali oleh Paul Ginnis dan merupakan suatu pembelajaran yang mengedepankan kepada aktivitas dan kerja sama siswa dalam mencari, menjawab dan melaporkan informasi dari berbagai sumber dalam sebuah suasana permainan yang mengarah pada pacuan kelompok melalui aktivitas kerja tim dan kecepatannya. Quick on the draw menginginkan agar siswa bekerja sama secara kooperatif pada kelompok-kelompok kecil dengan tujuan untuk menjadi kelompok pertama yang menyelesaikan satu set pertanyaan (Ginnis, 2008). Dengan demikian, model pembelajaran Quick on The Draw melatih siswa untuk belajar secara mandiri pada sumber bukan pada guru dengan aktivitas kerja kelompok.

Sintak pembelajaran kooperatif tipe Quick on The Draw (Ginnis, 2008) adalah : 
(a) Guru menyiapkan satu set pertanyaan mengenai materi yang akan dipelajari. Tiap pertanyaan harus di kartu terpisah.Setiap kelompok mempunyai satu set kartu sendiri dengan warna yang berbeda. Setiap set pertanyaan sebaiknya di kartu dengan warna berbeda dan diletakkan di meja guru.

(b) Guru membagi siswa ke dalam kelompok yang heterogen.

(c) Guru memberikan setiap kelompok sumber materi. Sumber materi bisa berupa halaman tertentu dari buku teks yang biasanya.

(d) Guru menjelaskan aturan permainan.

(e) Pada saat guru mengucapkan kata "mulai", salah satu perwakilan masing-masing kelompok "lari" ke meja guru dan mengambil pertanyaan pertama menurut warna mereka dan membawa kartu tersebut ke kelompok mereka masing-masing.

(f) Dengan menggunakan sumber materi yang telah diberikan, kelompok tersebut mencari dan menulis jawaban di lembar terpisah.

(g) Hasil jawaban kelompok dibawa ke gurunya oleh perwakilan kelompok. Guru memeriksa jawaban. Jika jawaban akurat dan lengkap, perwakilan kelompok diperbolehkan mengambil kartu pertanyaan berikutnya. Jika ada jawaban yang tidak akurat atau tidak lengkap maka guru meminta perwakilan kelompok kembali ke kelompok mereka dan mencoba lagi.

(h) Kelompok pertama yang menjawab semua pertanyaan adalah pemenangnya.

(i) Guru kemudian membahas semua pertanyaan dan meminta siswa untuk membuat catatan.

(j) Guru bersama - sama dengan murid memberikan kesimpulan.

Model pembelajaran Quick on The Draw memiliki beberapa keunggulan, yaitu (Ginnis, 2008):

(a) Aktivitas ini mendorong kerja kelompok semakin efisien, semakin cepat kemajuannya.

(b) Memberikan pengalaman mengenai tentang macam - macam keterampilan membaca, yang didorong oleh kecepatan aktivitas ditambah belajar mandiri, membaca pertanyaan dengan hati-hati, menjawab pertanyaan dengan tepat, membedakan materi yang penting dan tidak.

(c) Membantu siswa membiasakan diri untuk belajar pada sumber, tidak hanya pada guru.

(d) Sesuai bagi siswa dengan karakter kinestetik yang tidak dapat duduk diam selama lebih dari dua menit.
Model Pembelajaran SAVI (Somatic, Auditory, Visual, dan Intellectual)

SAVI (Somatic, Auditory, Visual dan Intellectual) merupakan model pembelajaran yang menekankan bahwa belajar haruslah memanfaatkan semua alat indra yang dimiliki peserta didik. Sesuai singkatannya pembelajaran SAVI terdiri dari empat unsur yaitu Somatis yang dapat diartikan belajar dengan bergerak dan berbuat, Auditori artinya belajar melalui berbicara dan mendengar, Visual artinya belajar dengan mengamati dan menggambarkan serta Intelektual yaitu belajar dengan memecahkan masalah (Meier, 2002). Adapun karakteristik unsur-unsur tersebut secara rinci adalah sebagai berikut (Meier, 2002).

(a) Somatis

Somatis berasal dari bahasa yunani yang memiliki arti tubuh. Dalam hal pembelajaran, belajar somatis berarti belajar dengan melibatkan fisik dan menggunakan tubuh (indera peraba, kinestetis, praktis) sewaktu belajar secara berkala.

(b) Auditory

Berpikir melalui auditory lebih kuat dari apa yang kita sadari. Melalui pendengaran, kita menangkap dan menyimpan informasi yang diberikan. Kemudian saat mengungkapan kembali dengan berbicara, beberapa area penting di otak menjadi aktif. Dalam kaitannya dengan pembelajaran, guru dapat merancang pelajaran yang menarik dengan merangsang auditory siswa dengan cara mendorong siswa untuk mengungkapkan pemikiran mereka. Pembelajaran auditory merupakan pembelajaran paling baik melalui mendengar dan berbicara.

(c) Visual

Visual berarti belajar dengan mengamati dan menggambarkan. Sesuatu yang berupa visual bersifat konkrit dan lebih mudah untuk di ingat. Siswa dapat memproses informasi pembelajaran dengan melihat secara visual seperti contoh dari dunia nyata, diagram, peta gagasan, ikon, gambar dari segala macam hal ketika sedang belajar.

(d) Intelektual

Intelektual adalah belajar dengan merenung, mencipta, dan memecahkan masalah sehingga belajar mempunyai makna. Intelektual melibatkan pikiran sebagai sarana manusia untuk berpikir, menyatukan pengalaman dan belajar. Belajar dengan intelektual melibatkan pikiran untuk menciptakan pembelajarannya sendiri sehingga belajar tidak hanya menyimpan informasi tetapi kearah pembelajaran yang 
bermakna melalui pengetahuan dan nilai yang dapat dipraktikkan.

Langkah-langkah model pembelajaran SAVI terbagi menjadi 4 tahap, yaitu (Meier, 2002):

\section{Preparation Stage}

Tahap ini merupakan tahap dimana guru mempersiapkan siswa untuk belajar yaitu dengan merangsang minat siswa agar lebih termotivasi melakukan pembelajaran. Pada tahap ini, guru dapat memberikan apersepsi serta tujuan pembelajaran, dan membangkitkan minat dan rasa ingin tahu siswa terhadap pembelajaran.

2. Presentation Stage

Tahap ini merupakan tahap dimana guru membantu siswa menemukan cara belajar yang menarik dan menyenangkan dengan melibatkan semua pancaindera.

3. Practice Stage

Tahap ini merupakan tahap dimana guru membantu siswa mengintegrasikan pengetahuan yang diperoleh dengan berbagai cara.

4. Performance Stage

Tahap ini merupakan tahap dimana guru membantu siswa dalam menerapkan dan mengembangkan pengetahuan yang mereka peroleh terhadap pekerjaan sehingga proses pembelajaran akan lebih melekat dan bermakna.

Secara keseluruhan, pelaksanaan kegiatan ini berjalan dengan lancar dan tidak mengalami hambatan. Beberapa peserta memberikan pertanyaan kepada narasumber dan melibatkan proses diskusi. Dengan adanya kegiatan ini, diharapkan dapat memotivasi guru-guru matematika SMP sekabupaten Banjar untuk memperluas pengetahuan mereka mengenai jenis-jenis model pembelajaran untuk diterapkan dalam pembelajaran matematika. Adapun pelaksanaan kegiatan pelatihan dapat dilihat pada gambar berikut.

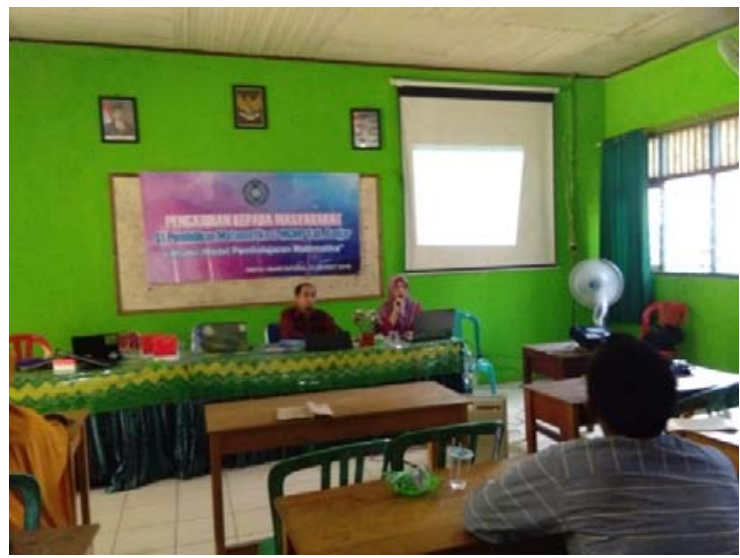

Gambar 1. Penjelasan terkait model-model pembelajaran oleh narasumber

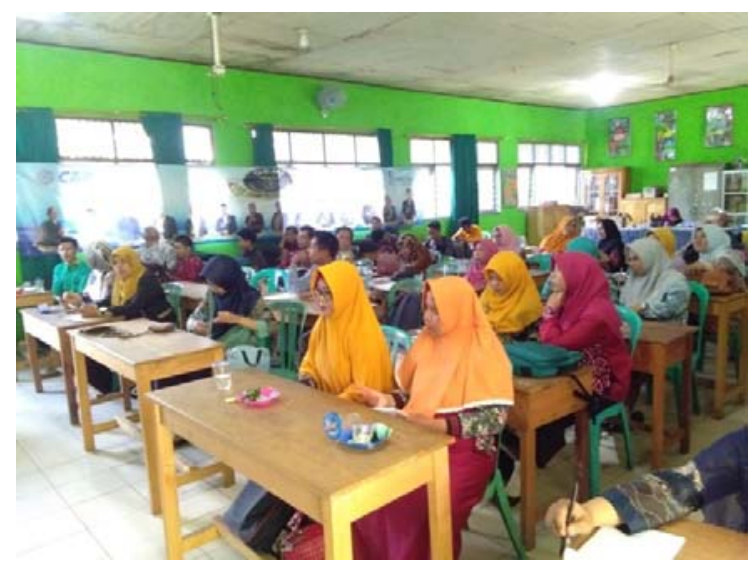

Gambar 2. Peserta pelatihan model-model pembelajaran

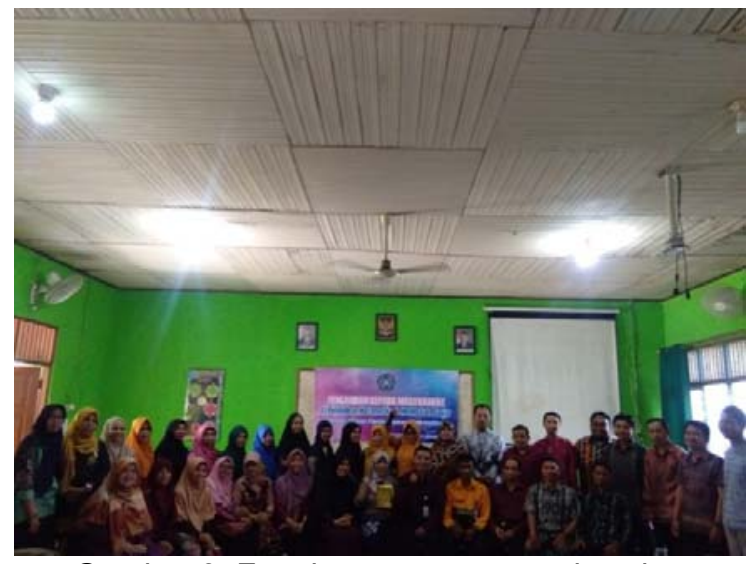

Gambar 3: Foto bersama narasumber dan peserta

\section{SIMPULAN DAN SARAN}

Kesimpulan dari hasil kegiatan pengabdian ini adalah sebagai berikut.

1. Kegiatan yang dilakukan berupa pelatihan model-model pembelajaran yang ditujukan kepada guru-guru matematika SMP sekabupaten Banjar bertempat di SMPN 1 Martapura pada hari kamis tanggal 21 Maret 2019. Kegiatan ini dihadiri oleh 44 orang guru matematika.

2. Adapun materi yang diberikan pada saat kegiatan adalah a) pengertian model pembelajaran beserta kaitannya dengan pendekatan, strategi, dan metode pembelajaran; b) jenis-jenis model pembelajaran yaitu Quick on the draw dan SAVI.

3. Kegiatan ini berjalan dengan lancar dan berpotensi memotivasi guru-guru matematika SMP sekabupaten Banjar untuk memperluas pengetahuan mereka mengenai jenis-jenis 
model pembelajaran untuk diterapkan dalam pembelajaran matematika.

Saran yang dapat diberikan terhadap kegiatan ini adalah hendaknya dilakukan simulasi oleh peserta dan ditinjau langsung oleh narasumber. Tujuannya agar peserta mempunyai bayangan dalam menerapkan model-model pembelajaran di kelas.

\section{DAFTAR RUJUKAN}

Ginnis, P. (2008). Trik dan Taktik Mengajar Strategi Meningkatkan Pencapaian Pengajaran di Kelas. Jakarta: Indeks.

Kusrini, Manoy, J. T., Susanah, \& Wijayanti, P. (2015). Strategi Pembelajaran Matematika. Tangerang Selatan: Universitas Terbuka.

Majid, A. (2013). Strategi Pembelajaran. Bandung: PT Remaja Rosdakarya .

Meier, D. (2002). The Accelerated Learning Hand Book. Panduan Kreatif dan Efektif Merancang Program Pendidikan dan Penelitian. Bandung: Kaifa. 